\title{
The Relationship Between Serum Angiogenic Factor Levels and Disease Activity in Rheumatoid Arthritis
}

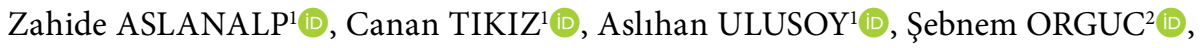 \\ Aysun BILLGİ YEDEKCİ ${ }^{3}$ (D) Cevval ULMAN ${ }^{3}$ (D) \\ ${ }^{1}$ Department of Physical Medicine and Rehabilitation, Manisa Celal Bayar University Faculty of Medicine, Manisa, Turkey \\ ${ }^{2}$ Department of Radiodiagnostic, Manisa Celal Bayar University Faculty of Medicine, Manisa, Turkey \\ ${ }^{3}$ Department of Biochemistry, Manisa Celal Bayar University Faculty of Medicine, Manisa, Turkey
}

\begin{abstract}
Objectives: This study aims to evaluate the relationship between serum angiogenic factor levels and disease activity in patients with rheumatoid arthritis (RA) using both clinical and dynamic wrist magnetic resonance imaging (MRI) data.

Patients and methods: Simultaneous serum angiogenesis markers [vascular endothelial growth factor (VEGF), angiopoietin-1 (ANG1), ANG2, and tyrosine-protein kinase receptor for angiopoietin (Tie-2)] were studied in 40 patients with RA (13 males, 27 females; mean age $51.1 \pm 10.8$ years; range, 23 to 69 years) and 20 healthy controls ( 11 males, 9 females; mean age $47.3 \pm 12.8$ years; range, 29 to 69 years) and dynamic contrast-enhanced wrist MRI was performed in 40 RA patients and seven controls. Rate of early in $55^{\text {th }}$ second (REE) and Relative enhancement (REt) values were calculated from the signal time curve values obtained from the analysis of images. In clinical assessment, duration of morning stiffness, patient pain assessment [visual analog scale (VAS)], physician and patient global assessments (VAS) were recorded. The number of tender joints and swollen joints were determined. Disease activity score 28 and Ritchie scores were calculated. Health assessment questionnaire was used for functional evaluation. Anti-cyclic citrullinated peptide, rheumatoid factor, erythrocyte sedimentation rate and high sensitive C-reactive protein analyses were performed. Results: Serum VEGF, REE and REt values were significantly higher in RA patients than healthy controls $(p=0.002, p=0.00, p=0.00$, respectively). There was no significant correlation between serum angiogenesis markers and clinical parameters or REE and REt ( $p>0.05$ ). VEGF value correlated positively with disease duration $(p=0.024)$.
\end{abstract}

Conclusion: Serum VEGF was higher in RA patients. While its level was associated with disease duration, no significant correlation was found with disease activity. As a diagnostic test, dynamic contrast-enhanced MRI was a valuable method for showing disease activity. Keywords: Disease activity, dynamic contrast-enhanced magnetic resonance imaging, rheumatoid arthritis, vascular endothelial growth factor.

Rheumatoid arthritis (RA) affects mainly the synovial tissue, resulting in hypertrophic synovial membrane (pannus) invasion-associated joint and cartilage damage of the joint cartilage. ${ }^{1-3}$ Neovascularization is necessary for the continuation of oxygen and nutrient support of the growing pannus, the transport of inflammatory cells in the inflamed synovium and the continuation of the chronic inflammatory condition. ${ }^{1,3-7}$ Therefore, synovial angiogenesis plays a key role in the formation and continuation of rheumatoid pannus. Synovial angiogenesis is achieved by the balance between various cytokines, inhibitors and activator factors. Vascular endothelial growth factor (VEGF) has a central role in angiogenesis. VEGF and members of the angiopoietin family and

Received: February 06, 2019 Accepted: September 04, 2019 Published online: January 08, 2020

Correspondence: Aslıhan Ulusoy, MD. Manisa Celal Bayar Üniversitesi Tıp Fakültesi Fiziksel Tıp ve Rehabilitasyon Anabilim Dalı, 45030 Yunusemre, Manisa, Türkiye. Tel: +90 236 - 2360330 / 3364 e-mail: draslihancileli@hotmail.com

Aslanalp Z, Tıkız C, Ulusoy A, Orguc Ş, Bilgi Yedekci A, Ulman C. The Relationship Between Serum Angiogenic Factor Levels and Disease Activity in Rheumatoid Arthritis. Arch Rheumatol 2020;35(3):416-425. 
tyrosine-protein kinase receptor for angiopoietin (Tie-2) are the main pro-angiogenic factors. ${ }^{5}$

The effects of VEGF include proliferation and migration of endothelial cells and increase in the vascular permeability. Angiopoietin-1 (ANG1) works synergistically with VEGF to support stabilization and maturation of newly formed vessels. It is believed that angiopoietin-2 (ANG2) is a natural antagonist of ANG1, which sensitizes endothelial cells against the effects of VEGF. In RA, ANG1 level is higher than ANG2 and Tie-2 pathway induced by ANG1 is dominant in neovascularization. ${ }^{8}$ There are studies in the literature showing the elevation of VEGF, ANG1, ANG2 and Tie-2 in synovial tissue in RA patients. ${ }^{2,8-10}$ However, the number of studies evaluating these parameters simultaneously with serum and clinical and radiological findings is very few.

Studies have been carried out to demonstrate that magnetic resonance imaging (MRI) is more sensitive than direct imaging and clinical examination in the early detection and subsequent follow-up of synovitis, bone marrow edema, and bone erosions in RA. ${ }^{11,12}$ Dynamic contrastenhanced MRI is an important method for demonstrating disease activity. This is based on the acquisition of images in sequence with rapid shots taken every few seconds during and after the infusion of gadolinium-diethylenetriamine pentaacetic acid (Gd-DTPA). In contrast images, time-dependent changes in the signal intensity of the synovial membrane are recorded and then these images allow analysis of the time-line of the synovial spread. Contrast ratio is correlated with synovial volume, erosion, vascularity, capillary permeability and metabolic activity, and with bone marrow edema and erosion, indicating that rapid contrasting tissue is associated with erosive disease. ${ }^{13-16}$ In this study, we aimed to evaluate the relationship between serum angiogenic factor levels and disease activity in patients with RA using both clinical and dynamic wrist MRI data.

\section{PATIENTS AND METHODS}

This study was conducted at Manisa Celal Bayar University Faculty of Medicine between January 2009 and June 2011. The minimum sample size required for the research was calculated using power analysis and the minimum sample size for each group was determined as 20 , with a power of $70 \%$, alpha $=0.05$ and effect size $=0.80$. The study group (group 1 ) included 40 patients (13 males, 27 females; mean age $51.1 \pm 10.8$ years; range, 23 to 69 years), twice as much as the control group, diagnosed with RA according to the 1987 ACR diagnostic criteria, while the control group (group 2) included 20 healthy volunteers (11 males, 9 females; mean age $47.3 \pm 12.8$ years; range, 29 to 69 years). Groups 1 and 2 were advised to avoid intensive activity for the wrists within 24 hours before the examination. ${ }^{16}$ The volunteers in group 2 were recruited from healthy hospital workers similar to the patient group in terms of age and sex. Patients with known additional inflammatory disease or malignant disease story were excluded. The demographic and clinical evaluations of the patients were performed by the same physiatrist. Age, sex, duration of illness (months), duration of morning stiffness (minutes), and medications were questioned. The patients participating in the study were antitumor necrosis factor (anti-TNF) naive patients. The patients were divided into three categories according to the treatment they received: those who did not use drugs, those using one diseasemodifying antirheumatic drug (DMARD), or those using two or more DMARDs. The study protocol was approved by the Manisa Celal Bayar University Faculty of Medicine Ethics Committee. A written informed consent was obtained from each participant. The study was conducted in accordance with the principles of the Declaration of Helsinki.

Visual analog scale (VAS) was used in the evaluation as follows: pain assessment (0: no pain, 10: unbearable pain), assessment of the general condition of the patient (0: very good, 10: severely poor), and the physician's assessment of the patient (0: very good, 10: severely poor). Disease activity was assessed by disease activity score 28 (DAS28) and Ritchie score. The 28 joints used in DAS28 calculation were individually examined for swelling and sensitivity. ${ }^{17}$ A DAS28 was calculated by entering the data into the software in a computer program, including the number of swollen joints, number of sensitive joints, sedimentation, and the patient's global assessment (VAS). DAS28 value higher than 5.1 
was assessed as high disease activity, between 3.2-5.1 as moderate disease activity, between 2.6-3.2 as mild disease activity, and between $0-2.6$ as remission. The joints assessed on the Ritchie score was rated between 0 and 3 on the sensitivity scale after finger pressure was applied on the joints. ${ }^{18}$ The functional status of the patients was questioned by the health assessment questionnaire (HAQ) index including a total of 20 questions about dressing, self-care, getting up, eating, walking, hygiene, reaching, gripping and difficulty in normal daily activities in the last one week. ${ }^{19}$

The erythrocyte sedimentation rate (ESR) of both groups was assessed by Westergren method, high sensitive $\mathrm{C}$-reactive protein ( $\mathrm{HsCRP}$ ) by nephelometric method, immunoglobulin $M$ rheumatoid factor (RF) by nephelometric method and anti-cyclic citrullinated peptide (anti-CCP) by enzyme-linked immunosorbent assay (ELISA) method.

Blood samples were centrifuged for serum VEGF, ANG1, ANG2, and Tie-2 concentrations and serum samples were stored at $-20{ }^{\circ} \mathrm{C}$ and assayed by R\&D Systems ELISA kits (Minneapolis, MN, USA).

A dynamic contrast-enhanced MRI of handwrists was performed in $40 \mathrm{RA}$ patients and seven healthy volunteers. Dynamic contrast-enhanced MRI was performed in more severely affected hand-wrists of patients with active RA and patients with symmetric hand-wrist involvement, while dominant hand-wrist imaging was performed in control patients.

Imaging of the subjects was performed by General Electric Signa HDx 1.5 Tesla brand MR device (Milwaukee, Wisconsin, USA) with superconductive equipment and a limb spiral. The imaging area was adjusted to cover from the carpal bones of the wrist to the proximal interphalangeal joints (PIF) joints. After wrist positioning, images were obtained in pre-contrast coronal T1A fast spin-echo sequences (TR: $360 \mathrm{~ms}$, time to echo (TE): min full, Matrix: $352 \times 256$, number of acquisitions (NEx): 2 , field of view (FOV): $16 \mathrm{~cm}$, Thickness: $2.5 / 0.3 \mathrm{~mm}$ and short T1 inversion recovery time to repeat (Tr): 3,825 ms, TE: $35 \mathrm{~ms}$, inversion time (TI): 145. Matrix: $288 \times 192$, NEx: 2, Thickness: 2.5/0.3 mm).

Three-dimensional dynamic time resolved imaging of contrast kinetics (TRICKS) sequence (Flip angle: 30, TE: min full, Matrix: 256×192 NEX: 1, FOV: 17, Thickness: $2.6 \mathrm{~mm}, 16$ sections) was used for dynamic contrast-enhanced MRI after intravenous (IV) contrast (Gd-DTPA) infusion. In this sequence, sectional images were obtained by taking 16 coronal images at each phase and repeating each phase at intervals of about 9.7 seconds. The oil-printed TRICKS sequence used in dynamic images was repeated once before and 47 times after the contrast. In all cases, $0.1 \mathrm{mmol} / \mathrm{kg}$ Gd-DTPA (MultiHance) was administered at a rate of $2 \mathrm{~mL} / \mathrm{second}$
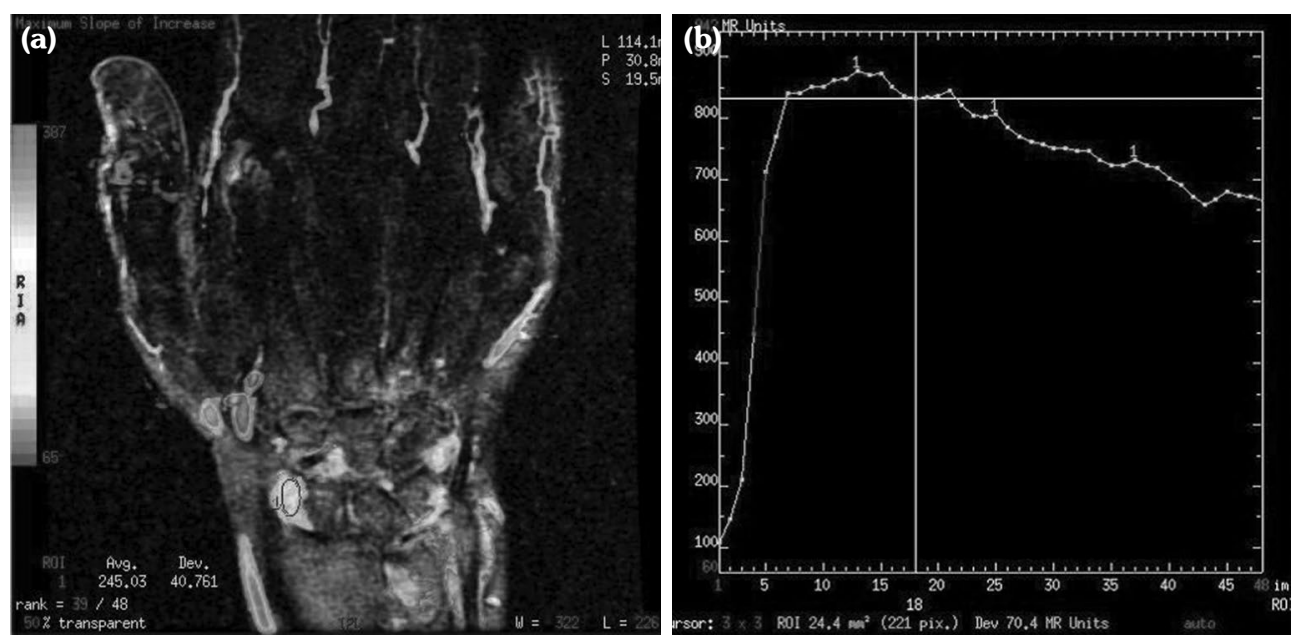

Figure 1. (a) Color map of wrist dynamic contrast-enhanced magnetic resonance imaging and (b) 48-phase signal time curve. 
with $25 \mathrm{~mL}$ saline in an autologous injector as IV contrast medium. The examination took 15 minutes in total.

Dynamic contrast-enhanced MR base images were examined using the Advantage Workstation 4.4 software (Milwaukee, Wisconsin, USA). Dynamic contrast-enhanced MRI studies were evaluated by a single blinded radiologist. In each case, a maximum synovial involvement area on the wrist was selected for analysis (Figure 1). Signal time curves were obtained by placing a circular region of interest that would cover two-thirds of the selected region.

The phase to be measured for early contrast enhancement was selected as the phase after 55 seconds (S55). When the time signal curves are colored according to the maximum slope of increase, $55^{\text {th }}$ second was chosen as it was determined to be the time interval where contrasting increases the fastest in these phase of cases.

Early and relative contrast ratios were calculated from the obtained curve. Rate of early enhancement (REE) was calculated according to $\mathrm{REE} 55=(\mathrm{S} 55-\mathrm{S} 0) /(\mathrm{S} 0 \times 55) \times 100 \%$ for $55^{\text {th }}$ second. According to the same formula, the relative enhancement in $t$ seconds (REt) was calculated according to the formula $\mathrm{REt}=(\mathrm{St}-\mathrm{S} 0) /$ $\mathrm{S} 0 \times 100 \%$ for time $\mathrm{t}$. In these formulas, S0 and St represent the signal intensity of the image before the contrast injection and after $t$ seconds, respectively (the MR signal in phase reaching the signal time curve maximum).

\section{Statistical analysis}

The SPSS version 16.0 Windows software (SPSS Inc., Chicago, IL, USA) was used for the statistical analysis of the obtained data. Whether the variables show normal distribution or not was analyzed by the Shapiro-Wilk test. Since the variables did not show normal distribution, non-parametric tests, which were more suitable than statistical tests, were used. Mann-Whitney $\mathrm{U}$ test was used in comparison of patients with healthy volunteers as well as in binary group comparisons. Kruskal-Wallis $\mathrm{H}$ test was used to compare more than two groups. Spearman correlation analysis was used to determine the relationship between numerical variables. $\mathrm{P}$ value $<0.05$ was considered statistically significant for all tests.

\section{RESULTS}

No statistically significant difference was found regarding age, sex and body mass index between the two groups ( $p=0.096, p=0.246$ and $p=0.950$, respectively). When laboratory data were compared, ESR, HsCRP values, RF and anti-CCP titrations were higher in group 1 than group $2(p<0.001)$ (Table 1$)$.

The average disease duration of group 1 was $28.8 \pm 24.7$ months. The mean DAS28 score of group 1 was $5.0 \pm 1.3$, the mean HAQ score was $0.7 \pm 0.5$, and the mean Ritchie score was 11.5 \pm 5.9 . Thirty-four patients (85\%) were on medication, 22 were receiving monotherapy, and 12 were receiving combination therapy.

Table 1. Comparison of age, sex, body mass index, and laboratory findings between group 1 and group 2

\begin{tabular}{|c|c|c|c|c|c|c|c|}
\hline & \multicolumn{3}{|c|}{ Group $1(n=40)$} & \multicolumn{3}{|c|}{ Group $2(\mathrm{n}=20)$} & \multirow[b]{2}{*}{$p$} \\
\hline & $\mathrm{n}$ & $\%$ & Mean \pm SD & $\mathrm{n}$ & $\%$ & Mean \pm SD & \\
\hline Age (year) & & & $51.1 \pm 10.8$ & & & $47.3 \pm 12.8$ & 0.096 \\
\hline $\begin{array}{l}\text { Sex } \\
\text { Female } \\
\text { Male }\end{array}$ & $\begin{array}{l}27 \\
13\end{array}$ & $\begin{array}{l}67.5 \\
32.5\end{array}$ & & & $\begin{array}{c}9 \\
11\end{array}$ & $\begin{array}{l}45 \\
55\end{array}$ & 0.246 \\
\hline Body mass index $\left(\mathrm{kg} / \mathrm{m}^{2}\right)$ & & & $26.4 \pm 3.8$ & & & $26.2 \pm 3.0$ & 0.950 \\
\hline Erythrocyte sedimentation rate $(\mathrm{mm} / \mathrm{h})$ & & & $31.2 \pm 18.0$ & & & $12.8 \pm 7.8$ & $<0.001$ \\
\hline High sensitive C-reactive protein (mg/L) & & & $7.6 \pm 6.7$ & & & $2.2 \pm 0.5$ & $<0.001$ \\
\hline Anti-cyclic citrullinated peptide (U/mL) & & & $249.8 \pm 208.8$ & & & $20.0 \pm 0.0$ & $<0.001$ \\
\hline Rheumatoid factor (IU/mL) & & & $136.2 \pm 203.9$ & & & $9.0 \pm 0.0$ & $<0.001$ \\
\hline
\end{tabular}


Table 2. Comparison of dynamic contrast-enhanced magnetic resonance imaging findings and angiogenesis factors between group 1 and group 2

\begin{tabular}{|c|c|c|c|}
\hline & Group 1 & Group 2 & \\
\hline & Mean \pm SD & Mean \pm SD & $p$ \\
\hline Rate of early enhancement & $7.6 \pm 4.4$ & $0.8 \pm 0.5$ & 0.000 \\
\hline Relative enhancement in $t$ seconds & $687.3 \pm 275.1$ & $170.6 \pm 97.3$ & 0.000 \\
\hline Vascular endothelial growth factor $(\mathrm{pg} / \mathrm{mL})$ & $523.7 \pm 319.1$ & $286.7 \pm 222.2$ & 0.002 \\
\hline Angiopoietin $1(\mathrm{pg} / \mathrm{mL})$ & $61282.1 \pm 18984.7$ & $58700.4 \pm 20636.2$ & 0.466 \\
\hline Angiopoietin $2(\mathrm{pg} / \mathrm{mL})$ & $4055.2 \pm 1301.9$ & $3948.0 \pm 1488.6$ & 0.644 \\
\hline Tyrosine-protein kinase receptor for angiopoietin $(\mathrm{ng} / \mathrm{mL})$ & $31.3 \pm 9.6$ & $33.0 \pm 17.0$ & 0.826 \\
\hline
\end{tabular}

Dynamic contrast-enhanced MRI REE and REt values and VEGF levels of group 1 were significantly higher than group 2 (Table 2). ANG1 and ANG2 were higher in patients with
RA. However, this difference was not statistically significant ( $p>0.05)$.

Rate of early enhancement value was significantly correlated with all clinical parameters

Table 3. Correlation of patients with angiogenesis markers and magnetic resonance imaging and clinical findings

\begin{tabular}{|c|c|c|c|c|c|c|}
\hline & $\begin{array}{l}\text { Dynamic } \\
\text { MRI REE }\end{array}$ & $\begin{array}{l}\text { Dynamic } \\
\text { MRI REt }\end{array}$ & VGEF & ANG 1 & ANG 2 & Tie-2 \\
\hline \multicolumn{7}{|c|}{ Duration of morning stiffness } \\
\hline $\mathrm{r}$ & 0.428 & 0.208 & -0.041 & -0.178 & -0.218 & 0.013 \\
\hline $\mathrm{p}$ & 0.006 & 0.98 & 0.800 & 0.271 & 0.176 & 0.936 \\
\hline \multicolumn{7}{|c|}{ Number of swollen joints } \\
\hline r & 0.591 & 0.364 & 0.045 & 0.021 & 0.030 & 0.117 \\
\hline $\mathrm{p}$ & 0.000 & 0.021 & 0.781 & 0.896 & 0.855 & 0.474 \\
\hline \multicolumn{7}{|c|}{ Number of sensitive joints } \\
\hline r & 0.464 & 0.329 & -0.021 & -0.022 & -0.020 & 0.055 \\
\hline $\mathrm{p}$ & 0.003 & 0.038 & 0.895 & 0.891 & 0.904 & 0.736 \\
\hline \multicolumn{7}{|c|}{ Pain assessment of the patient } \\
\hline r & 0.422 & 0.297 & 0.084 & -0.060 & -0.083 & 0.119 \\
\hline $\mathrm{p}$ & 0.007 & 0.063 & 0.607 & 0.711 & 0.609 & 0.463 \\
\hline \multicolumn{7}{|c|}{ General assessment of patient condition } \\
\hline r & 0.423 & 0.275 & -0.043 & -0.068 & -0.050 & -0.105 \\
\hline $\mathrm{p}$ & 0.007 & 0.085 & 0.791 & 0.678 & 0.758 & 0.520 \\
\hline \multicolumn{7}{|c|}{ General assessment by the physician } \\
\hline $\mathrm{r}$ & 0.384 & 0.221 & 0.111 & 0.067 & 0.035 & -0.011 \\
\hline $\mathrm{p}$ & 0.015 & 0.171 & 0.497 & 0.683 & 0.832 & 0.945 \\
\hline \multicolumn{7}{|c|}{ DAS28 score } \\
\hline$r$ & 0.514 & 0.315 & 0.084 & -0.060 & -0.083 & 0.119 \\
\hline $\mathrm{p}$ & 0.001 & 0.047 & 0.607 & 0.711 & 0.609 & 0.463 \\
\hline \multicolumn{7}{|c|}{ Ritchie score } \\
\hline r & 0.575 & 0.449 & -0.041 & -0.178 & -0.218 & 0.013 \\
\hline $\mathrm{p}$ & 0.000 & 0.004 & 0.800 & 0.271 & 0.176 & 0.936 \\
\hline \multicolumn{7}{|c|}{ HAQ score } \\
\hline r & 0.439 & 0.455 & 0.045 & 0.021 & 0.030 & 0.117 \\
\hline $\mathrm{p}$ & 0.005 & 0.003 & 0.781 & 0.896 & 0.855 & 0.474 \\
\hline
\end{tabular}

MRI: Magnetic resonance imaging; REE: Rate of early enhancement, REt: Relative enhancement in t seconds; VEGF: Vascular endothelial growth factor; ANG: Angiopoietin; Tie-2: Tyrosine-protein kinase receptor for angiopoietin; DAS28: Disease activity score 28; HAQ: Health assessment questionnaire; R: Spearman correlation coefficient. 


\begin{tabular}{|c|c|c|c|c|c|c|c|}
\hline & \multicolumn{2}{|c|}{ Without drug $(\mathrm{n}=6)$} & \multicolumn{2}{|c|}{ Monotherapy $(n=22)$} & \multicolumn{2}{|c|}{ Combination therapy $(\mathrm{n}=12)$} & \multirow[b]{2}{*}{$p$} \\
\hline & Mean \pm SD & Min-Max & Mean \pm SD & Min-Max & Mean \pm SD & Min-Max & \\
\hline $\begin{array}{l}\text { Duration of morning } \\
\text { stiffness }\end{array}$ & $60.0 \pm 62.3$ & $10-180$ & $33.0 \pm 46.7$ & $0-120$ & $10.0 \pm 18.6$ & $0-60$ & 0.026 \\
\hline $\begin{array}{l}\text { Number of swollen } \\
\text { joints }\end{array}$ & $8.7 \pm 5.1$ & $1-15$ & $2.9 \pm 3.2$ & $0-10$ & $3.9 \pm 3.7$ & $0-10$ & 0.038 \\
\hline $\begin{array}{l}\text { Number of sensitive } \\
\text { joints }\end{array}$ & $14.5 \pm 7.9$ & $1-21$ & $10.8 \pm 8.3$ & $1-27$ & $13.1 \pm 8.9$ & $0-26$ & 0.529 \\
\hline $\begin{array}{l}\text { General assessment of } \\
\text { patient condition }\end{array}$ & $5.8 \pm 1.2$ & $4-7$ & $3.6 \pm 1.8$ & $1-7$ & $4.3 \pm 2.1$ & $1-7$ & 0.041 \\
\hline $\begin{array}{l}\text { General assessment } \\
\text { by the physician }\end{array}$ & $5.7 \pm 1.0$ & $4-7$ & $3.5 \pm 1.8$ & $1-6$ & $4.2 \pm 2.1$ & $1-7$ & 0.033 \\
\hline $\begin{array}{l}\text { Pain assessment of the } \\
\text { patient }\end{array}$ & $5.7 \pm 1.2$ & $4-7$ & $3.7 \pm 1.9$ & $1-7.5$ & $4.5 \pm 1.9$ & $1-7$ & 0.072 \\
\hline DAS28 score & $6.1 \pm 1.3$ & $4.06-7.48$ & $4.7 \pm 1.2$ & $2.72-7.24$ & $5.0 \pm 1.5$ & $2.64-6.89$ & 0.102 \\
\hline Ritchie score & $17.0 \pm 7.1$ & $5-26$ & $10.2 \pm 5.2$ & $3-23$ & $10.9 \pm 5.5$ & $2-17$ & 0.067 \\
\hline HAQ score & $0.9 \pm 0.5$ & $0.25-1.62$ & $0.6 \pm 0.57$ & $0-2$ & $0.6 \pm 0.4$ & $0-1.37$ & 0.429 \\
\hline VEGF (pg/mL) & $387.3 \pm 319.7$ & $162.52-926.21$ & $586.9 \pm 354.5$ & $120.39-1460$ & $476.0 \pm 232.6$ & $93.36-892.31$ & 0.341 \\
\hline ANG1 (pg/mL) & $55032.0 \pm 15531.2$ & $\begin{array}{l}40372.25- \\
80179.12\end{array}$ & $66097.4 \pm 21212.0$ & $\begin{array}{l}24398.63- \\
115656.58\end{array}$ & $55579.0 \pm 14354.4$ & $\begin{array}{l}36412.78- \\
81210.54\end{array}$ & 0.119 \\
\hline ANG2 (pg/mL) & $3696.3 \pm 1255.4$ & $\begin{array}{l}2453.56- \\
5723.26\end{array}$ & $4384.5 \pm 1388.08$ & $\begin{array}{l}1584.82- \\
7094.11\end{array}$ & $3630.9 \pm 1063.6$ & $\begin{array}{l}2169.10- \\
5519.82\end{array}$ & 0.181 \\
\hline Tie-2 (ng/mL) & $32.8 \pm 7.5$ & $24.10-41.12$ & $32.8 \pm 11.6$ & $15.70-58.03$ & $27.9 \pm 5.3$ & $18-35.41 G$ & 0.427 \\
\hline
\end{tabular}

$(p<0.05)$ (Table 3). REt was found to be significantly related to the number of swollen and sensitive joints, DAS28, Ritchie and HAQ scores $(p<0.05)$. No correlations were detected between the levels of angiogenesis markers of the patients and clinical parameters (DAS28, Ritchie scores etc.). In group 1, VEGF value correlated positively with disease duration $(p=0.024, r=0.355)$.

In the laboratory findings, we only found a positive correlation between anti-CCP and ANG1 $(\mathrm{r}=0.341, \mathrm{p}=0.031)$. There was no significant correlation between REE and REt and laboratory findings ( $>0.05)$ or angiogenesis markers ( $p>0.05)$.

Patients were studied in two subgroups: early $(<2$ years, $n=21)$ and late $(>2$ years, $n=19)$ disease periods. ${ }^{25}$ There was a statistically significant difference between early and late disease periods for VEGF $(386.5 \pm 231.5$ and $675.3 \pm 338.9$, respectively; $p=0.003$ ). There was no statistically significant difference between early and late disease periods for REE and REt ( $p>0.05$ ) Significant correlation was found between REE value and serum VEGF level in late term patients $(r=0.460)(p=0.047)$.
Rate of early enhancement and REt values showed a statistically significant difference between non-drug patients, monotherapy patients and combined therapy patients $(p=0.024$, $p=0.027$, respectively). The non-drug patients had significantly higher REE and REt values than patients who received monotherapy $(p=0.007$, $p=0.016$, respectively) and combined therapy ( $p=0.025, p=0.031$, respectively). Comparison of clinical and angiogenesis factors according to the treatment type is given in Table 4.

\section{DISCUSSION}

Angiogenesis is an important pathogenetic process for synovitis persistence and disease activity in proliferative and destructive inflammatory synovitis such as RA. Displaying angiogenesis by imaging or biochemical markers may provide more objective data than the standard methods we are using today to monitor disease activity and response to treatment. In this study, we evaluated the levels of serum angiogenesis markers (VEGF, ANG1, ANG2 and Tie-2), conventional indexes 
(clinical, laboratory), and dynamic contrastenhanced MRI parameters in patients with RA and in the control group simultaneously. We concluded that in RA patients, levels of REE, REt and serum VEGF were significantly higher than the control group. However, there was no correlation with serum angiogenesis marker (VEGF, ANG1, ANG2, Tie-2) levels and DAS28.

In order to evaluate the patients homogeneously, we divided them into two subgroups as early and late disease periods according to the disease duration. We found higher values of VEGF in late term patients. We correlated the serum angiogenesis markers REE and REt values into two subgroups. There was no correlation between patients in the early period while significant correlation was found between VEGF and REE values in late term patients. This correlation and our higher detection of VEGF in the late disease period may be an indication that the formation of unstable and permeable vessels formed by the increased VEGF effect in the vascular bed and this causes more and faster spread of contrast.

The Ballara et al. ${ }^{20}$ study, which divided RA patients into early and late period categories, has demonstrated that patients in the early period had higher levels of serum VEGF compared to patients in the late period. In the literature, studies involving measurements of serum VEGF levels before and after DMARD and infliximab therapy have shown a decrease in serum VEGF levels as a correlation with improvement in clinical and laboratory disease activity markers after treatment and it was thought that VEGF levels could be a follow-up parameter., ${ }^{4,51-24}$ However, we found that serum VEGF levels in patients with early period RA were lower than patients with late period ( $>2$ years) RA. Similarly, a study by Ozgonenel et al. ${ }^{25}$ including $40 \mathrm{RA}$ patients and 38 controls have found that VEGF levels were higher in late period patients. They have stated that this was caused by poor disease control of late period RA patients in spite of DMARD treatment. In our study, a similar situation existed. Despite the medical care provided, a majority of the patients had medium and high activity according to DAS28, which supports this sentiment.
There is a limited number of studies in which serum levels of VEGF, ANG1, ANG2 and Tie-2 angiogenesis markers have been evaluated together, and compared with disease activity and activity in the synovial tissue detected by MRI. Westra et $a l .{ }^{26}$ have found that serum VEGF and ANG2 were higher in 176 newly diagnosed RA patients than healthy controls; particularly, ANG2 levels were shown to be correlated with disease activity. Clavel et al. ${ }^{27}$ have observed 310 early arthritis patients with a mean disease duration of 3.1 months for one year, correlating serum VEGF, ANG1 levels with inflammation parameters and bone destruction. In our study, only serum levels of VEGF were significantly higher than the control group. ANG1 and ANG2 were higher than controls, while not statistically significantly. Also, there was no significant differences in Tie-2 serum levels.

When we examined the relationship between angiogenesis biomarkers and laboratory parameters, we found a significant correlation between anti-CCP and ANG1. ANG1, which is expressed from the invasive surface of the pannus, was found responsible for the cartilage matrix destruction that increased in culture. In a study of cell signaling mechanisms of ANG1 to determine the direct effects of ANG1 on cartilage destruction and synovium overgrowth, in addition to cytokines such as interleukin-1 alpha and TNF-alpha, the ANG1/Tie-2 signal was reported to be a factor responsible for destruction of the cartilage matrix in rheumatoid joint independent of angiogenesis. ${ }^{28}$ The predictive value of anti$\mathrm{CCP}$ in RA radiological progression has been demonstrated by several studies and it has been reported that more severe radiological damage develops in anti-CCP positive patients. ${ }^{29}$ This correlation, which we have observed, suggests that ANG1 may be important for predicting erosive alterations and progression, while further research is needed in this regard.

Ejbjerg et al. ${ }^{30}$ noted that mild synovitis or small bone erosions may be seen on MRI in healthy controls, while signal curves for synovitis and bone erosion on dynamic MRI are uncommon or absent. Histological studies have also shown that dynamic contrast-enhanced MRI is an effective method of showing inflammation of the stiffness ratio and disease activity. ${ }^{31-33}$ In a study of Ostergaard et al. ${ }^{34}$ including 
17 patients with RA and 25 patients with osteoarthritis, dynamic contrast-enhanced MRI of knee joint stiffness ratio and microscopically graded synovial inflammation were found to be correlated. We also found a positive correlation between the clinical activity parameters of the patients such as the number of swollen and sensitive joints, DAS28, Ritchie and HAQ scores; and dynamic contrast-enhanced MRI REE and REt values. A higher correlation of REE with clinical and disease activity in RA suggests that it is more specific than REt; however, further work is needed in this regard. Our results support that dynamic MRI is a reliable method of delivering objective data to reflect disease activity in $\mathrm{RA}$. The fact that there is no difference between REE and REt values in early and late disease periods may be due to synovial inflammation being affected by changes in disease activity independently of disease duration. In our study, REE and REt values were significantly higher in patients who did not receive medical treatment compared with patients receiving monotherapy and combined treatment. Although it is an expensive method as revealed in many studies, the efficacy of treatment was demonstrated with dynamic contrast-enhanced MRI measurements. ${ }^{35-37}$

This study has some limitations. Patients' data were not compared before and after treatment and only cross-sectional data were assessed. For this reason, it was not possible to evaluate the efficacy of treatment with these parameters. Moreover, our sample size was small and the patients consisted of a heterogeneous group.

In conclusion, our data suggest that serum VEGF was associated with RA disease duration, but not correlated with disease activity. Furthermore, serum VEGF level was found to be significantly correlated with REE value which evaluated synovial activity in late term patients. If larger series confirm that serum VEGF and ANG1 concentrations are predictive of joint damage, this may support a more aggressive treatment regime when high serum levels are detected. Also, monitoring of serum angiogenic markers may help to determine the suppression of vascular pannus formation and cartilage defect in future studies.

\section{Declaration of conflicting interests}

The authors declared no conflicts of interest with respect to the authorship and/or publication of this article.

\section{Funding}

The authors received no financial support for the research and/or authorship of this article.

\section{REFERENCES}

1. Gibofsky A. Epidemiology, pathophysiology, and diagnosis of rheumatoid arthritis: A Synopsis. Am J Manag Care 2014;20:S128-35.

2. Paleolog EM. The vasculature in rheumatoid arthritis: cause or consequence? Int J Exp Pathol 2009;90:249-61.

3. Marrelli A, Cipriani P, Liakouli V, Carubbi F, Perricone $\mathrm{C}$, Perricone R, et al. Angiogenesis in rheumatoid arthritis: a disease specific process or a common response to chronic inflammation? Autoimmun Rev 2011;10:595-8.

4. Paleolog EM. Angiogenesis in rheumatoid arthritis. Arthritis Res 2002;4:S81-90.

5. Clavel G, Boissier MC. Angiogenesis markers in rheumatoid arthritis. Future Rheumatol 2008;3:153-9.

6. Koch $\mathrm{AE}$. The role of angiogenesis in rheumatoid arthritis: recent developments. Ann Rheum Dis 2000;59:i65-71.

7. Szekanecz Z, Besenyei T, Szentpétery A, Koch $\mathrm{AE}$. Angiogenesis and vasculogenesis in rheumatoid arthritis. Curr Opin Rheumatol 2010;22:299-306.

8. Shahrara S, Volin MV, Connors MA, Haines GK, Koch AE. Differential expression of the angiogenic Tie receptor family in arthritic and normal synovial tissue. Arthritis Res 2002;4:201-8.

9. Scott BB, Zaratin PF, Colombo A, Hansbury MJ, Winkler JD, Jackson JR. Constitutive expression of angiopoietin- 1 and -2 and modulation of their expression by inflammatory cytokines in rheumatoid arthritis synovial fibroblasts. J Rheumatol 2002;29:230-9.

10. Lee YH, Bae SC. Correlation between circulating VEGF levels and disease activity in rheumatoid arthritis: a meta-analysis. Z Rheumatol 2018;77:240-8.

11. Olech E, Crues JV 3rd, Yocum DE, Merrill JT. Bone marrow edema is the most specific finding for rheumatoid arthritis (RA) on noncontrast magnetic resonance imaging of the hands and wrists: a comparison of patients with RA and healthy controls. J Rheumatol 2010;37:265-74.

12. Østergaard M, Ejbjerg B, Szkudlarek M. Imaging in early rheumatoid arthritis: roles of magnetic resonance imaging, ultrasonography, conventional radiography and computed tomography. Best Pract Res Clin Rheumatol 2005;19:91-116. 
13. Orguc S, Tikiz C, Aslanalp Z, Erbay PD. Comparison of OMERACT-RAMRIS scores and computer-aided dynamic magnetic resonance imaging findings of hand and wrist as a measure of activity in rheumatoid arthritis. Rheumatol Int 2013;33:1837-44.

14. Hodgson RJ, O'Connor P, Moots R. MRI of rheumatoid arthritis image quantitation for the assessment of disease activity, progression and response to therapy. Rheumatology (Oxford) 2008;47:13-21.

15. Hermann KG, Backhaus M, Schneider U, Labs K, Loreck D, Zühlsdorf $S$, et al. Rheumatoid arthritis of the shoulder joint: comparison of conventional radiography, ultrasound, and dynamic contrastenhanced magnetic resonance imaging. Arthritis Rheum 2003;48:3338-49.

16. Cimmino MA, Innocenti S, Livrone F, Magnaguagno F, Silvestri E, Garlaschi G. Dynamic gadoliniumenhanced magnetic resonance imaging of the wrist in patients with rheumatoid arthritis can discriminate active from inactive disease. Arthritis Rheum 2003;48:1207-13.

17. Prevoo ML, van 't Hof MA, Kuper HH, van Leeuwen MA, van de Putte LB, van Riel PL. Modified disease activity scores that include twenty-eight-joint counts. Development and validation in a prospective longitudinal study of patients with rheumatoid arthritis. Arthritis Rheum 1995;38:44-8.

18. Ritchie DM, Boyle JA, McInnes JM, Jasani MK, Dalakos TG, Grieveson P, et al. Clinical studies with an articular index for the assessment of joint tenderness in patients with rheumatoid arthritis. Q J Med 1968;37:393-406

19. Bruce B, Fries JF. The Health Assessment Questionnaire (HAQ). Clin Exp Rheumatol 2005;23:S14-8.

20. Ballara S, Taylor PC, Reusch P, Marmé D, Feldmann M, Maini RN, et al. Raised serum vascular endothelial growth factor levels are associated with destructive change in inflammatory arthritis. Arthritis Rheum 2001;44:2055-64.

21. Taylor PC. Serum vascular markers and vascular imaging in assessment of rheumatoid arthritis disease activity and response to therapy. Rheumatology (Oxford) 2005;44:721-8.

22. Carvalho JF, Blank M, Shoenfeld Y. Vascular endothelial growth factor (VEGF) in autoimmune diseases. J Clin Immunol 2007;27:246-56.

23. Paleolog E. Target effector role of vascular endothelium in the inflammatory response: insights from the clinical trial of anti-TNF alpha antibody in rheumatoid arthritis. Mol Pathol 1997;50:225-33.

24. Strunk J, Bundke E, Lange U. Anti-TNF-alpha antibody Infliximab and glucocorticoids reduce serum vascular endothelial growth factor levels in patients with rheumatoid arthritis: a pilot study. Rheumatol Int 2006;26:252-6.

25. Ozgonenel L, Cetin E, Tutun S, Tonbaklar P, Aral $\mathrm{H}$, Guvenen $\mathrm{G}$. The relation of serum vascular endothelial growth factor level with disease duration and activity in patients with rheumatoid arthritis. Clin Rheumatol 2010;29:473-7.

26. Westra J, de Groot L, Plaxton SL, Brouwer E, Posthumus MD, Kallenberg CG, et al. Angiopoietin-2 is highly correlated with inflammation and disease activity in recent-onset rheumatoid arthritis and could be predictive for cardiovascular disease. Rheumatology (Oxford) 2011;50:665-73.

27. Clavel G, Bessis N, Lemeiter D, Fardellone P, Mejjad $\mathrm{O}$, Ménard JF, et al. Angiogenesis markers (VEGF, soluble receptor of VEGF and angiopoietin-1) in very early arthritis and their association with inflammation and joint destruction. Clin Immunol 2007;124:158-64.

28. Hashiramoto A, Sakai C, Yoshida K, Tsumiyama $\mathrm{K}$, Miura $\mathrm{Y}$, Shiozawa $\mathrm{K}$, et al. Angiopoietin 1 directly induces destruction of the rheumatoid joint by cooperative, but independent, signaling via ERK/ MAPK and phosphatidylinositol 3-kinase/Akt. Arthritis Rheum 2007;56:2170-9.

29. Meyer O, Labarre C, Dougados M, Goupille P, Cantagrel A, Dubois A, et al. Anticitrullinated protein/ peptide antibody assays in early rheumatoid arthritis for predicting five year radiographic damage. Ann Rheum Dis 2003;62:120-6.

30. Ejbjerg B, Narvestad E, Rostrup E, Szkudlarek M, Jacobsen S, Thomsen HS, et al. Magnetic resonance imaging of wrist and finger joints in healthy subjects occasionally shows changes resembling erosions and synovitis as seen in rheumatoid arthritis. Arthritis Rheum 2004;50:1097-106.

31. König H, Sieper J, Wolf KJ. Rheumatoid arthritis: evaluation of hypervascular and fibrous pannus with dynamic MR imaging enhanced with Gd-DTPA. Radiology 1990;176:473-7.

32. Ostergaard M, Stoltenberg M, Henriksen O, Lorenzen I. Quantitative assessment of synovial inflammation by dynamic gadolinium-enhanced magnetic resonance imaging. A study of the effect of intra-articular methylprednisolone on the rate of early synovial enhancement. Br J Rheumatol 1996;35:50-9.

33. Axelsen MB, Stoltenberg M, Poggenborg $\mathrm{RP}$, Kubassova $\mathrm{O}$, Boesen $\mathrm{M}$, Bliddal $\mathrm{H}$, et al. Dynamic gadolinium-enhanced magnetic resonance imaging allows accurate assessment of the synovial inflammatory activity in rheumatoid arthritis knee joints: a comparison with synovial histology. Scand J Rheumatol 2012;41:89-94.

34. Ostergaard M, Stoltenberg M, Løvgreen-Nielsen P, Volck B, Sonne-Holm S, Lorenzen I. Quantification of synovistis by MRI: correlation between dynamic and static gadolinium-enhanced magnetic resonance imaging and microscopic and macroscopic signs of synovial inflammation. Magn Reson Imaging 1998;16:743-54.

35. Reece RJ, Kraan MC, Radjenovic A, Veale DJ, O'Connor PJ, Ridgway JP, et al. Comparative 
assessment of leflunomide and methotrexate for the treatment of rheumatoid arthritis, by dynamic enhanced magnetic resonance imaging. Arthritis Rheum 2002;46:366-72.

36. Axelsen MB, Poggenborg RP, Stoltenberg M, Kubassova O, Boesen M, Hørslev-Petersen K, et al. Reliability and responsiveness of dynamic contrast- enhanced magnetic resonance imaging in rheumatoid arthritis. Scand J Rheumatol 2013;42:115-22.

37. Tam LS, Griffith JF, Yu AB, Li TK, Li EK. Rapid improvement in rheumatoid arthritis patients on combination of methotrexate and infliximab: clinical and magnetic resonance imaging evaluation. Clin Rheumatol 2007;26:941-6. 